\title{
Advancement flap in the management of chronic anal fissure: a prospective study
}

\author{
Rosalia Patti · Giovanni Guercio · Valentina Territo • \\ Paolo Aiello · Giuseppe Livio Angelo • \\ Gaetano Di Vita
}

Received: 13 November 2011 / Accepted: 14 March 2012/Published online: 10 April 2012

(C) Springer-Verlag 2012

\begin{abstract}
Lateral internal sphincterotomy is the surgical treatment of choice of chronic anal fissure after failure of conservative measures. Several randomized trials identified an overall risk of incontinence of $10 \%$ mostly for flatus. Fissurectomy is the most commonly used procedure to preserve the integrity of the anal sphincters. However, a possible complication is keyhole defect that may lead to faecal soiling. In this study, chronic anal fissure (CAF) was treated by fissurectomy and anal advancement flap to preserve the anatomo-functional integrity of sphincters and to reduce healing time and the risk of anal stenosis. In patients with hypertonia, surgical treatment was combined with chemical sphincterotomy by injection of botulinum toxin to enhance tissue perfusion. Forty eight patients with CAF underwent fissurectomy and anal advancement flap. In 22 subjects with hypertonia of the internal anal sphincter, intrasphincter injection of $30 \mathrm{UI}$ of botulinum toxin at the completion of the surgical operation was used. All patients were followed up to 24 months. Since the first defecation, the intensity and duration of pain were significantly reduced. Two patients had urinary retention, five had infections and three had partial breakdowns. No anal stenosis, keyhole deformity or necrosis flap was recorded. At the 24 months follow-up visit, anal incontinence was similar to those detected preoperatively. Only four recurrences were detected at 18 and 20 months. After medical treatment failure, fissurectomy with advancement flap is a valid sphincter-conserving procedure for treatment of
\end{abstract}

R. Patti · G. Guercio - V. Territo · P. Aiello ·

G. L. Angelo · G. Di Vita ( $₫)$

Division of General Surgery, Department of Surgical

and Oncologic Science, University of Palermo,

Via L. Giuffrè ${ }^{\circ}{ }^{5}, 90127$ Palermo, Italy

e-mail: divitagaetano@libero.it anterior or posterior CAF, regardless of hypertonia of the internal anal sphincter.

Keywords Chronic anal fissure - Advancement flap · Fissurectomy

\section{Introduction}

Anal fissure is a linear split or breach in the lining of the transition zone between the skin and mucous of the anal canal. It has an elliptical form, with its major axis vertical and a size of around $0.5-1 \mathrm{~cm}$. Fissures are classified as acute or chronic. Acute fissure tends to heal spontaneously with topical steroids, local anaesthetic and bulk laxatives within 6 weeks and looks similar to paper [1]. The chronological definition is rather loose, but most surgeons regard persistence beyond 6 weeks as a reasonable time when an acute fissure, unlikely to heal with conservative treatment, may be considered chronic [1]. Morphologically, the presence of visible transverse internal anal sphincter fibres at the base of a fissure indicates chronicity and provides a more clear-cut definition [1]. Associated features include indurates edges, a sentinel pile and a hypertrophied anal papilla.

Chronic anal fissure (CAF) is usually associated with internal anal sphincter (IAS) hypertonia, the relief of which is considered central to promote fissure healing. First-line treatment of CAF to decrease hypertonia of the internal anal sphincter is medical. After pharmacological sphincterotomy, the healing rate of CAF ranges from 30 to $96 \%$, whereas transitory minor incontinence for flatus and soiling has been reported in a few cases. Surgical treatment generally recommended is anal lateral sphincterotomy that seems to be the manoeuvre of choice after the failure of 
conservative treatment resulting in success rates above $95 \%$ [2]. However, it may cause incontinence. As indicated by Nelson [3] in a recent systematic review of randomized surgical trials, after sphincterotomy the overall risk of incontinence is about $10 \%$, mostly to flatus without any specification of the duration of this problem (transitory or permanent). However, it is a common belief that the risk of permanent incontinence is about $1 \%$. Nonetheless, this does not take into account the normal weakening of the sphincter with age and the possibility of future anorectal surgery, radiation or obstetrical trauma. Therefore, the risk of incontinence after lateral internal sphincterotomy should be taken into account looking at the life span of the patient [4].

Fissurectomy is the procedure most used to preserve the integrity of anal sphincters, although it has been rarely used alone. In fact, the possible complication of keyhole defect that may lead to faecal soiling limits its use. Recently, to reduce the incidence of complications, it has been associated with pharmacological sphincterotomy or with advancement flap showing good results.

The aim of this study was to evaluate the efficacy of fissurectomy with anal advancement flap in the treatment of CAF. The primary end point was fissure healing and the secondary end point included symptoms relief (bleeding, pain, pruritus) and immediate and long-term complications (incontinence, anal stenosis, keyhole deformity, urinary retention and recurrence).

\section{Materials and methods}

From January 2002 to January 2008, 106 patients who failed medical therapy underwent surgical treatment: 48 subjects underwent fissurectomy and anal advancement flap; the remaining 58 patients were treated with a tailored sphincterotomy. Since 2002, 26 patients with anterior and posterior CAF without hypertonia of IAS underwent fissurectomy combined with $\mathrm{V}-\mathrm{Y}$ advancement flap [5, 6], while 10 patients with anterior CAF and hypertonia of IAS underwent fissurectomy combined with advancement flap and injections of $30 \mathrm{UI}$ of botulinum toxin [7]; posterior CAF with hypertonia was treated with a tailored sphincterotomy. According to positive results obtained since 2006, a further 12 patients with posterior CAF and hypertonia of IAS underwent fissurectomy combined with anal advancement flap and injection of 30 UI of botulinum toxin (Table 1).

All subjects gave written informed consent and the local ethics committee approved the study. Exclusion criteria were the presence of multiple and lateral fissures, chronic fistulas in ano, syphilis, inflammatory bowel disease, anal abscess or malignant disease. CAFs resistant to medical
Table 1 Site, tone of internal anal sphincter of 48 chronic anal fissures (CAFs) treated with sparing saving sphincter procedures

\begin{tabular}{lllll}
\hline CAF site & Sphincter tone & no & $\%$ & Treatment \\
\hline Anterior & Normo-hypotonia & 16 & 33 & $\mathrm{~F}+\mathrm{A}$ \\
Posterior & Normo-hypotonia & 10 & 21 & $\mathrm{~F}+\mathrm{A}$ \\
Anterior & Hypertonia & 10 & 21 & $\mathrm{~F}+\mathrm{A}+$ Tox \\
Posterior & Hypertonia & 12 & 25 & $\mathrm{~F}+\mathrm{A}+\mathrm{Tox}$ \\
\hline
\end{tabular}

$A$ anal advancement flap, $F$ fissurectomy, Tox botulinum toxin

treatment were defined as those that failed healing after well-practised topical medical therapy and high fibre dietary supplementation. Preoperative anorectal manometry was performed after appropriate time of cessation of medical treatment. The manometry was carried out by a manometric sensor with $2.1 \mathrm{~mm}$ external diameter with four circle orifices and with a latex microballoon at its extremity (Marquat C87, Boissy, St-Leger, France). The machine was connected to a polygraph (Narco, Byo-System MMS 200, Houston, TX, USA), using the station pullthrough method with perfusion of normal saline and the patient lying in the right lateral position. Maximum resting pressure (MRP) was defined as maximum pressure detected on resting. Data collected by our anorectal pathophysiology laboratory, according to others [8], showed that the normal range of MRP values was from 45 to $85 \mathrm{mmHg}$. CAFs without hypertonia have been defined as those in which MRP values are $<85 \mathrm{mmHg}$ [8]. All patients underwent fissurectomy in the gynaecological position under spinal anaesthesia. An Eisenhammer anal speculum was gently inserted into the anal canal. After injection of $5 \mathrm{ml}$ of a local anaesthetic solution constituting $100 \mathrm{mg}$ of cloridrate mepivacain and $0.025 \mathrm{mg}$ of $\mathrm{L}$-adrenaline, the fibrotic edges were excised with a scalpel until a normal nonfibrotic anodermal tissue showed sufficient bleeding. The sentinel skin tag and hypertrophied papilla at the level of dentate line when present were excised. The granulation tissue at the base of the fissure was curetted until there were clean muscle fibres of the IAS. There was no use of diathermy and careful attention was given not to damage the IAS. Standard advancement flap was performed using a flap of healthy skin tissue extending from about $2-3 \mathrm{~cm}$ from the anal verge, which was mobilized and then advanced with its blood supply to fill the defect. The flap was secured without tension to the anal canal and the skin was closed tension free in a $\mathrm{V}-\mathrm{Y}$ manner with rapid absorbable suture behind the advanced flap. In patients with anterior and posterior CAF with hypertonia of the IAS, after the fissurectomy and the anal advancement flap, an injection of botulinum toxin A (Botox, Allergan, Westport, Ireland) stored at $-20{ }^{\circ} \mathrm{C}$ and diluted in saline to $50 \mathrm{UI} / \mathrm{ml}$ was performed into IAS with a 27 -gauge needle. Each patient received a total of $30 \mathrm{UI}$ of botulinum toxin 
equally divided on either side of the midline. According to others, the site of injection depends on the location of the fissure and it should be anterior for posterior fissure and posterior for anterior ones [9]. None of the patients assumed concomitant oral medications that could interfere with the action of type A botulinum toxin (aminoglycosides, baclofen, dantrolene, diazepam) and there was no known hypersensitivity to any component of botulinum toxin formulation. Before surgery, all patients received a small volume of phosphate-saline enema. Metronidazole was administered intravenously at a dose of $500 \mathrm{mg} 1 \mathrm{~h}$ before surgery. Subsequently, it was administered per os at the dosage of $250 \mathrm{mg}$ for 7 days three times daily. During the first 2 weeks after the operation, patients took variable doses of psyllium fibre. A laxative preparation (sennosides) was given orally to subjects who had not yet passed stools 3 days after surgery. Enema, suppositories and all rectal manipulations were avoided. Immediately after surgery, all patients received $100 \mathrm{mg}$ of diclofenac intramuscularly for analgesia and were instructed to take only $100 \mathrm{mg}$ of nimesulide tablets as requested. Fissure healing was defined as a complete epithelization of the advancement flap. Both duration and intensity of pain post-defecation were evaluated after surgical treatment. Pain intensity was scored with a visual analog scale (VAS) from 0 to 10 , where 0 corresponded to no pain and 10 to the worse pain conceivable [10]. Patients were discharged $24-48 \mathrm{~h}$ after surgery; afterward, they were examined in the outpatient clinic until the anal wound was completely healed. All patients were followed up to 24 months after surgery. The controls were made at distance of 1, 6, 12 and 24 months. Anal incontinence was assessed using the Pescatori grading system: A, incontinence for flatus and mucus; B, liquid stool; C, solid stool; and 1 for occasional, 2 for weekly and 3 for daily [11]. Independently of these scheduled appointments, patients were seen on request.

\section{Statistical analysis}

Continuous variables were expressed as mean and standard deviation, and qualitative data as absolute frequencies. Student's $t$ test with Welch correction was used to analyse the differences of pain score and pain duration at each registration point. Values of $p<0.05$ were considered to be statistically significant.

\section{Results}

Baseline characteristics of patients

The enrolled patients included 32 females and 16 males with a median age of 37 years (range 18-65). Bowel habitus was normal in 10 patients, constipation was detected in 36 subjects and diarrhoea in 2 patients in accordance with updated Rome diagnostic criteria, previously published [12]. Ten females were nulliparous, whereas 12 had given birth vaginally one time or more and 10 had caesarean delivery. The mean duration of symptoms was $12.3 \pm 5.1$ months. In $83 \%$ of the cases, the CAF had an hypertrophied anal papilla and in $73 \%$ of cases skin tags occurred. The more frequent symptom was pain (96\%), whereas bleeding and pruritus occurred, respectively, in 83 and $52 \%$.

The localization of CAF was anterior in 26 patients and posterior in 22 ; in 26 cases, there was normo-hypotonia. The unusually high rate of female sex and anterior CAF was due the fact that in our previous study design, the original indication to the advancement flap after fissurectomy was reserved only for female patients with anterior CAF (5). All patients underwent fissurectomy and V-Y advancement flap. Twenty two patients with hypertonia of the IAS were treated with injection of $30 \mathrm{U}$ of botulinum toxin (Table 1).

\section{Healing fissure and relief of symptoms}

All patients healed completely within 30 days after operation. None of the patients had diarrhoea and only two patients were referred for two defecations only in 1 day during the assessment time. The intensity and the duration of pain post-defecation was reduced significantly with respect to the preoperative values starting from the first defecation $(p<0.0001)$ (Fig. 1). None of the patients complained of pain, bleeding or pruritus 30 days after surgery. Analgesics consumption decreased significantly after the first defecation.

\section{Anal continence}

Preoperatively, seven patients were referred for anal incontinence. Among them, according to the Pescatori grading system [11], one subject was classified as A1, five

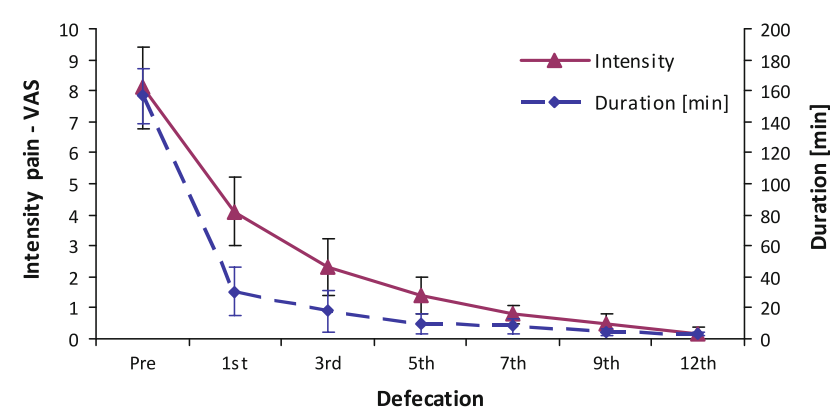

Fig. 1 Intensity and duration of pain related to defecation after fissurectomy and anal advancement flap 
Table 2 Patients with anal incontinence according to Pescatori grading score before and after surgical operation

\begin{tabular}{llllr}
\hline Time & A1 & A2 & A3 & Total \\
\hline Preoperative & 1 & 5 & 1 & 7 \\
At 1 month & 3 & 5 & 2 & 10 \\
At 6 months & 4 & 3 & 1 & 8 \\
At 12 months & 3 & 3 & 1 & 7 \\
At 24 months & 3 & 2 & 1 & 6 \\
\hline
\end{tabular}

as $\mathrm{A} 2$ and one as $\mathrm{A} 3$. One month after surgery, anal incontinence was referred in ten patients. At 24 months, only six patients referred to incontinence: three as A1, two as A2 and one as A3 (Table 2); at the initial presentation, all the six patients had complained of incontinence.

Complications and follow-up

Only minor complications were observed; in particular, five cases of infection and three of partial breakdown occurred. In all cases, the infection was superficial and did not need antibiotics administration. Two patients suffered from urinary retention. There were no cases of anal stenosis or keyhole deformity. No necrosis of the transposed flap was observed (Table 3 ).

At 24 months of follow-up, four recurrences were recorded $(8 \%)$. In two cases, primitive CAF was anterior without hypertonia of IAS; their recurrence was localized posteriorly with a normal value of IAS. In the third case, primitive CAF was anterior with hypertonia of IAS and the recurrence was lateral without hypertonia; the last patient had posterior primitive CAF with hypertonia of IAS and its recurrence was anterior with hypertonia. All patients with recurrence of CAF underwent medical treatment with improvement or healing.

\section{Discussion}

The data from this study underline that by avoiding sphincterotomy using a technique that preserves sphincter

Table 3 Postoperative complications and number of recurrences

\begin{tabular}{llr}
\hline Complications & Total & $\%$ \\
\hline Urinary retention & 2 & 4 \\
Anal stenosis & - & - \\
Keyhole deformity & - & - \\
Infection & 5 & 10 \\
Breakdown & 3 & 6 \\
Necrosis flap & - & - \\
Recurrences (24 months) & 4 & 8 \\
\hline
\end{tabular}

activity, good results may be achieved. In fact, all patients healed within 30 days from operation. At the 24-month follow-up, six patients reported anal incontinence that was already present before the surgical operation and there were only four recurrences. We have reported a low incidence of complications and no surgical re-operation was needed. Although wound infection and flap breakdown are known complications of anal advancement flap, in this study the incidence of breakdown was $3 / 58$ cases $(5.1 \%)$ in accordance with rates reported in the literature by Giordano et al. (5.9\%) [13], Chambers (5.5\%) [14] and Patel et al (8\%) [15]. On the other hand, the incidence of infection was $5 / 58$ cases $(8.6 \%)$, similar to that reported by Patel $(8 \%)$ [15].

Until now, the role of hypertonia of IAS is unclear: if it is a cause or an effect of CAF. During the last few decades, the treatment was aimed to reduce sphincter hypertonia with medical or surgical techniques. The first-line treatment of CAF is medical. However, surgical sphincterotomy represents the treatment of choice in case of failure of conservative measures. The sphincterotomy was described in 1951 by Eisenhammer; partial division of the internal sphincter muscle posterior has been a popular treatment for anal fissure for nearly two decades. However, several studies have reported prolonged healing times, postoperative pain and keyhole deformity [2]. Therefore, today this procedure is used rarely. In 1969, Notaras proposed lateral internal sphincterotomy. This technique is associated with fewer complications than posterior sphincterotomy, with immediate improvement of pain and success rate above $95 \%$ [2]. However, it is associated with significant incidence of postoperative incontinence ranging between 0 and $35 \%$ for flatus, 0 and $21 \%$ for liquid, and 0 and $5 \%$ for solid stools [4] with an overall incontinence risk as high as $10 \%$ [3]. Variations could be due to operative technique, length of follow-up or criteria used to define anal incontinence [16]. Nowadays, it is well known that faecal incontinence may occur many years after sphincter damage (i.e. anorectal surgery, radiation or obstetrical trauma). To minimize this risk, several authors have tried a more limited division of internal sphincter, a tailored or controlled sphincterotomy [17, 18]. Tailored sphincterotomy reduces the risk of incontinence, but may increase the incidence of recurrence $[17,18]$.

Fissurectomy is the surgical procedure most used to preserve structural and functional integrity of the IAS. Fissurectomy is the excision of the anal fissure and it can be associated with the removal of the hypertrophied anal papilla and the skin tags. Fissurectomy, as a wound debridement, removes the bradytrophic scar tissue and produces fresh wound edges, creating in essence an acute fissure. Fissure excision without a procedure on the IAS is an old operation and was supported by Ashton in 1854 . 
It was recognized as effective therapy for CAF for many years and afterwards it was abandoned due to its consequences, such as keyhole deformity that may lead to faecal incontinence [16]. Nevertheless, it has recently been reconsidered for treating CAF both in children and in adults with success [19-21]. To improve the results and to reduce the incidence of complications, the fissurectomy has been associated with pharmacological sphincterotomy. This treatment includes the advantages of fissurectomy as well as those of pharmacological sphincterotomy. Engel et al. [22] first described the combination of fissurectomy associated with chemical sphincterotomy. They combined local isosorbide dinitrate with fissurectomy in 15 patients and described healing rates of $100 \%$ within a follow-up of 29 months [22]. Few recent studies [4, 23-28] describe a combination of botulinum toxin A injections and fissurectomy with excellent results. This procedure allows healing by secondary intention, because it leaves the fissurectomy wound open. Only Witte et al. [28] prepared wound edges after fissurectomy and sutured it with absorbable sutures, reducing the time of healing.

To cover the exposed area after fissurectomy, an advancement skin graft has been mostly used. Only recently, a mucosal advancement flap has been used [29, 30]. The rationale of advancing flaps of skin and fat is based on introducing fresh blood supply to the ischaemic area of the fissure [2], reducing the time required for perianal wound healing and avoiding the risk of anal stenosis that follows healing by scarring [16]. This procedure has been performed selectively on patients with CAF without hypertonia of IAS [5, 6, 31-33] or extensively, independently of CAF side and sphincter tone [13, 14, 34-36]. The results obtained have been good; in particular, a high healing rate, reduced incidence of complications and recurrences and complete preservation of anal continence have been reported. In patients with dermal flap, Hancke et al. [36] in a comparative study between dermal flap coverage and lateral internal sphincterotomy reported a significant reduction of anal incontinence. However, to date published reports have been based only on a small sample size; only one study published in 1970 analysed a high number of procedures [35]. Giordano et al. [13] and Chambers et al. [14] showed excellent results, giving solid evidence that fissurectomy with anal advancement flap may be used as first-line treatment for all the CAFs.

Fissurectomy combined with anal advancement flap and injection of 30 UI of botulinum toxin in patients with posterior CAF with hypertonia of IAS, which until now has been used only by us, shows how the temporary reduction of the IAS tone, after injection of botulinum toxin, improves bloody flow and permits rooting of skin graft. At 24 months, there were only four recurrences not localized at the same initial sites. This occurrence is perhaps testament of the durability of the flap. The event that subsequently four patients developed new fissures suggests that this technique does not remove presumed causes of fissure like defecatory habit, stool consistency and sphincter tone [13]. According to other authors [31, 33-35], there was not a new case of incontinence; in fact, six patients with incontinence reported it before the surgical operation.

The studies on CAF treatment after failure of conservative measures using surgical techniques of sphincter sparing show excellent results in terms of healing rates and incidence of incontinence and recurrence. In conclusion, although some studies showed excellent results for the treatment of CAF independent of site, sex and sphincter tone, to date it seems opportune to offer fissurectomy combined with anal advancement flap only in patients with anterior CAF, in female patients and/or in the case of recurrence after sphincterotomy and after surgical operation in ano.

\section{Conflict of interest None.}

\section{References}

1. Lindsey I, Jones OM, Cunningham C, Mortensen NJ (2004) Chronic anal fissure. Br J Surg 91:270-279

2. Collins EE, Lund JN (2007) A review of chronic anal fissure management. Tech Coloproctol 11:209-223

3. Nelson R (2005) Operative procedure for fissure in ano. Cochrane Database Syst Rev 2:CD002199

4. Sileri P, Stolfi VM, Franceschilli L, Grande M, Di Giorgio A, D’Ugo S, Attinà G, D'Eletto M, Gaspari AL (2010) Conservative and surgical treatment of chronic anal fissure: prospective longer term results. J Gastrointest Surg 14:773-780

5. Patti R, Famà F, Barrera T, Migliore G, Di Vita G (2010) Fissurectomy and anal advancement flap for anterior chronic anal fissure without hypertonia of the internal anal sphincter in females. Colorectal Dis 12:1127-1130

6. Patti R, Famà F, Tornambè A, Restivo M, Di Vita G (2010) Early results of fissurectomy and advancement flap for resistant chronic anal fissure without hypertonia of the internal anal sphincter. Am Surg 76:206-210

7. Patti R, Famà F, Tornambè, Asaro G, Di Vita G (2010) Fissurectomy combined with anal advancement flap and injection of botulinum toxin in treatment of anterior chronic anal fissure with hypertonia of internal anal sphincter: a pilot study. Tech Coloproctol 14:31-36

8. Jones OM, Ramalingam T, Lindsey I, Cunningham C, George BD, Mortensen NJ (2005) Digital rectal examination of sphincter pressures in chronic anal fissure is unreliable. Dis Colon Rectum 48:349-352

9. Brisinda G, Cadeddu F, Brandara F, Maringa G, Vanella S, Nigro C, Maria G (2008) Botulinum toxin for recurrent anal fissure following lateral internal sphincterotomy. Br J Surg 95:774-778

10. Huskisson EC (1982) Measurement of pain. J Rheumatol 9:768-769

11. Pescatori M, Anastasio G, Bottini C, Mentasti A (1992) New grading and scoring for anal incontinence. Evaluation of 335 patients. Dis Colon Rectum 35:482-487 
12. Thompson WG, Longstreth GF, Drossman DA, Heaton KW, Irvine EJ, Muller-Lissner SA (1999) Functional bowel disorders and functional abdominal pain. Gut 45:II 43-II 47

13. Giordano P, Gravante G, Grondona P, Ruggiero B, Porret T, Lunnis PJ (2009) Simple cutaneous anal advancement flap for resistant chronic anal fissure: a prospective study. World J Surg 33:1058-1063

14. Chambers W, Sajal R, Dixon A (2010) V-Y advancement flap as first-line treatment for all chronic anal fissures. Int J Colorectal Dis 25:645-648

15. Patel SD, Oxenam T, Praveen BV (2011) Medium term results of anal advancement flap compared with lateral sphincterotomy for the treatment of anal fissure. Int $\mathbf{J}$ Colorectal Dis. doi: 10.1007/S00384-011-1234-4

16. Ayantunde AA, Debrah SA (2006) Current concepts in anal fissures. World J Surg 30:2246-2260

17. Cho DY (2005) Controlled lateral sphincterotomy for chronic anal fissure. Dis Colon Rectum 48:1037-1041

18. Mentes BB, Ege B, Leventoglu S, Oguz M, Karadag A (2005) Extent of lateral internal sphincterotomy: up to the dentate line or up to the fissure apex? Dis Colon Rectum 48:365-370

19. Aigner F, Conrad F (2008) Fissurectomy for treatment of chronic anal fissures. Dis Colon Rectum 51:1163

20. Meier zu Eissen J (2001) Chronic anal fissure, therapy. Kongressbd Dtsch Ges Chir Kongr 118:654-656

21. Mousavi SR, Sharifi M, Mehdikhah Z (2009) A comparison between the results of fissurectomy and lateral internal sphincterotomy in the surgical management of chronic anal fissure. J Gastrointest Surg 13:1279-1282

22. Engel AF, Eijsbouts QA, Balk AG (2002) Fissurectomy and isosorbide dinitrate for chronic fissure in ano not responding to conservative treatment. Br J Surg 89:79-83

23. Lindsey I, Cunningham C, Jones OM, Francis C, Mortensen NJ (2004) Fissurectomy-botulinum toxin: a novel sphincter-sparing procedure for medically resistant chronic anal fissure. Dis Colon Rectum 47:1947-1952

24. Baraza W, Boereboom C, Shorthouse A, Brown S (2008) The longterm efficacy of fissurectomy and botulinum toxin injection for chronic anal fissure in females. Dis Colon Rectum 51:239-243

25. Scholz T, Hetzer FH, Dindo D, Demartines N, Clavien PA, Hahlaser D (2007) Long-term follow-up after combined fissurectomy and Botox injection for chronic anal fissures. Int $\mathbf{J}$ Colorectal Dis 22:1077-1081

26. Arthur JD, Makin CA, El-Sayed TY, Walsh CJ (2008) A pilot comparative study of fissurectomy/diltiazem and fissurectomy/ botulinum toxin in the treatment of chronic anal fissure. Tech Coloproctol 12:331-336

27. Aivaz O, Rayhanabad J, Nguyen V, Haigh PI, Abbas M (2009) Botulinum toxin A with fissurectomy is a viable alternative to lateral internal sphincterotomy for chronic anal fissure. Am Surg 75:925-928

28. Witte ME, Klaase JM, Koop R (2010) Fissurectomy combined with botulinum toxin A injection for medically resistant chronic anal fissures. Colorectal Dis 12:163-169

29. Ouaïssi M, Giger U, Sielezneff I, Yawovi KA, Pamela A, Pirro N, Sastre B (2011) Mucosal advancement flap anoplasty for chronic anal fissure resistant to conservative therapy. World J Surg 35:900-904

30. Pigot F, Juguet F, Bouchard D, Castinel A, Vove JP (2011) Prospective survey of secondary bleeding following anorectal surgery in a consecutive series of 1,269 patients. Clin Res Hepathol Gastroenterol 35:41-47

31. Nyam DC, Wilson RG, Stewart KJ et al (1995) Island advancement flaps in the management of anal fissures. Br J Surg 82:326328

32. Pescatori M, Ayabaca SM, Cafaro D (2002) Tailored sphincterotomy or fissurectomy and anoplasty? Dis Colon Rectum 45: $1563-1564$

33. Kenefick NJ, Gee AS, Durdey P (2002) Treatment of resistant anal fissure with advancement anoplasty. Colorectal Dis 4:463466

34. Singh M, Sharma A, Gardiner A, Duthie GS (2005) Early results of a rotational flap to treat chronic anal fissures. Int J Colorectal Dis 20:339-342

35. Samson RB, Stewart WR (1970) Sliding skin grafts in the treatment of anal fissures. Dis Colon Rectum 13:372-375

36. Hancke E, Rikas E, Suchan K, Volke K (2010) Dermal flap coverage for chronic anal fissure: lower incidence of anal incontinence compared to lateral internal sphincterotomy after long-term follow-up. Dis Colon Rectum 53:1563-1568 